\title{
Towards Quest for Early Maturing Mungbean [Vigna radiata (L.) Wilczek] Lines with Improved Nutritional Quality and High Yield
}

\author{
Moushree Sarkar, Sambit Datta ${ }^{1}$, Sabyasachi Kundagrami
}

10.18805/IJARe.A-5788

\begin{abstract}
Background: Mungbean [Vigna radiata (L.) Wilczek], a rich source of protein, carbohydrate and different micronutrients, can play an important role in food security programmes. Enhancement of nutritional qualities via biofortification of existing varieties is a promising area of research.

Methods: In the current study, sixty one mungbean were taken to study different biochemical parameters and also to establish an inter-relationship of each parameter with yield and maturity.

Result: Results show that, nine lines, which included two germplasms namely, B1 and Pusa-9632 along with four mutants as well as three hybirds were found to have higher nutritional quality especially carbohydrate and protein content. Moreover, the mutants and segregants showed a higher nutritional value (\% increase) than the germplasms. In addition, correlation coefficient study ensured an interrelationship between agronomic and biochemical characters by reporting that the total starch and nitrogen content of mungbean seeds can serve as an excellent selection marker for improving seed yield.
\end{abstract}

Key words: Biochemical characterization, Germplasms, hybirds lines, Mungbean [Vigna radiata (L.) Wilczek], Mutant lines, Segregating lines.

\section{INTRODUCTION}

Food security has become a global concern. A recent conservative estimate indicates that as high as two billion people suffer globally from hunger and malnutrition (WHO 2017). Not only the availability of the right quantity of food is important, but also the quality of the food available needs due consideration. Important dietary proteins and other essential nutrients often lack in the food intake amongst a large section of the population. Grain legumes also known as pulses, have high levels of protein content which are rich in lysine as well as other minerals and nutrients which can supplement dietary deficiencies in undernourished populations (Singh 2017). In India, which on Global Hunger Index is positioned at $103^{\text {rd }}$ out of 119 countries, presents a dismal picture of hunger and malnutrition (Global Hunger Index 2018). Among Indians in general and specifically amongst the rural female population, the consumed food is deficient in essential dietary nutrients. This leads to malnourishment and causes different kinds of health issues (Kshatriya and Acharya 2016).

Mungbean [Vigna radiata (L.) Wilczek], is one of the most important grain legumes in Asia and especially India. It is a cheap source of easily digestible lysine rich proteins, as well as rich in other essential dietary nutrients. The protein quality of mungbean is better than other legumes (Anisha and Prema 2008). Apart from its protein content, mungbean seeds also contain fat, fibre, ash and carbohydrate (Grewal et al., 2006). A major carbohydrate constituent of mungbean is starch and amylose is the major component of this starch content of mungbean (Nair et al., 2013). From this, it is evident that improvement of mungbean crop both from an agronomic perspective as well as from a nutritional
Department of Genetics and Plant Breeding, Institute of Agricultural Science, University of Calcutta, 51/2, Hazra Road, Kolkata-700 019, West Bengal, India.

'Division of Plant Biology, Bose Institute, Kolkata-700 054, West Bengal, India.

Corresponding Author: Moushree Sarkar, Department of Genetics and Plant Breeding, Institute of Agricultural Science, University of Calcutta, 51/2, Hazra Road, Kolkata-700 019, West Bengal, India. Email: moushreesarkar88@gmail.com

How to cite this article: Sarkar, M., Datta, S. and Kundagrami, S. (2021). Towards Quest for Early Maturing Mungbean [Vigna radiata (L.) Wilczek] Lines with Improved Nutritional Quality and High Yield. Indian Journal of Agricultural Research. DOI: 10.18805/IJARe.A5788.

Submitted: 09-04-2021 Accepted: 05-07-2021 Online: 02-08-2021

perspective is essential. Despite its importance, progress in production and productivity of mungbean has been slow. The breeding programmes applied to mungbean so far have been purely conventional which has not been able to keep up with the ever increasing demands. In Indian agricultural systems, more importance is levied on increasing grain yield and crop productivity rather than enrichment of the nutrient quality, which will help to improve human health. This imbalance often gives rise to micronutrient malnutrition among the population. Hence, methods outlining the development of high yielding mungbean varieties with high nutritional quality have great relevance in fighting "micronutrient malnutrition" especially in poor and developing countries (Garg et al., 2018).

Biofortification is a process which refers to the development of nutritionally improved food crops (Shobha 
Rani et al., 2019). This may be achieved in existing varieties through agronomic practices, conventional breeding techniques, or modern biotechnological tools. In this study we aim to evaluate the nutritional quality of sixty one high yielding (seed yield $>20$ g plant $^{-1}$ ) extra short duration $(<60$ days) (Sarkar and Kundagrami 2017) mungbean accessions comprising of twenty mutants (Sarkar and Kundagrami 2018) and sixteen hybirds lines (Sarkar 2017) along with twenty five germplasms (which were the parental stock for the mutant and segregating lines, collected from all over India).

\section{MATERIALS AND METHODS}

\section{Experimental materials}

The experimental materials comprises of a total number of sixty one high productive short duration mungbean accessions (Table 1). The germplasm evaluation, mutation breeding and hybridization were conducted through Department of Genetics and Plant Breeding, Institute of Agricultural Science, University of Calcutta during 2016-2018 (Sarkar and Kundagrami 2017, 2018). First three generation of mutants $\left(\mathrm{M}_{1}-\mathrm{M}_{3}\right)$ were evaluated at Baruipur experimental farm of University of Calcutta and fourth $\left(\mathrm{M}_{4}\right)$ generation was at a farmer's field in Udaynarayanpur, Howrah, West Bengal. On the other hand crossing and evaluation of first generation hybirds were done at Baruipur, second generation $\left(\mathrm{F}_{2}\right)$ was evaluated at Udaynarayanpur and third $\left(F_{3}\right)$ generation was at another farmer's field at Arambagh. From $\mathrm{M}_{4}$ generation twenty high yielding early maturing plants were selected to procure $M_{5}$ seeds and from $F_{3}$ generation sixteen high yielding early maturing plants were selected to procure $\mathrm{F}_{4}$ seeds. The mutant and hybirds lines were considered to be stable lines after multilocation field trial followed by stability analysis (Sarkar 2017).

\section{Experimental methods}

\section{Field study}

Exhaustive field trials for the character evelution of all the 61 accessions were conducted in 2018 following RBD design with three replications at three different locations in the state of West Bengal, India, Information pertaining to each of the field is elaborated in Table 2. Seeds were sown in $3 \mathrm{~cm}$ deep pits along a line with pit to pit $20 \mathrm{~cm}$ spacing and line to line $30 \mathrm{~cm}$. Plants were raised and maintained according to the standard agronomic practices for mungbean cultivation (Department of Agriculture, Forestry and Fisheries 2010). At the time of maturity, days to maturity and seed yield plant $^{-1}$ (weight of total seeds of a single plant) were recorded from five randomly selected healthy plants from each replication of each accession.

\section{Nutritional characterization}

Freshly harvested seeds of all the experimental materials were cleaned, washed and dried to remove the extraneous material and then ground to form fine flour. The flour of each of the lines was analysed for total carbohydrate (Dubois et al., 1956), total starch (Hodge and Hofreiter 1962), amylose (Sadasivam and Manickam 1996), crude protein (Lowry et al., 1951), total free amino acid (Moore and Stein 1948) and total nitrogen content (AOAC 2000). 100mg flour was taken for each analysis for each accession. All the analysis was done with three replications and average value for each analysis was calculated for statistical analysis.

\section{Statistical analysis}

Data for field study and laboratory experiments were subjected to one way analysis of variance (ANOVA) and post hoc Duncan's Multiple Range Test using the statistical package of SPSS ver 21.0. Genetic variability estimates were calculated between all pairs of germplasms and lines by the Cluster analysis using SPSS ver 21.0 software. Principal component analysis (PCA) was done using Minitab ver 18.0 and Correlation coefficient study was done using SPAR 2.0 software.

\section{RESULTS AND DISCUSSION}

\section{Field study}

\section{Agronomic parameters study}

\section{Days to maturity}

Of all the Mungbean germplasms screened, Baruipur Local 2 (59 days) and B1(59 days) showed maximum significant reduction in days to maturity (Fig $1 \mathrm{~A}$ ). At the same time all the selected lines recorded maturity duration of less than 55 days. Among the mutants M2, M6, M7, M8, M9, M11, M12, M16 and M17 showed maturity duration of 53 days (Figure 1B) and of all the hybirds lines, $\mathrm{H} 10$ had the shortest maturity duration of 52 days (Fig 1C).

\section{Seed yield plant ${ }^{-1}$}

Evaluation of seed yield plant $^{-1}$ revealed that among the germplasms, UPM-99-3 (22.55g) showed significantly $(p<0.05)$ higher seed yield (Figure 1D) than others. Mutants namely M19 and M12 (34 g each respectively) along with hybirds plant $\mathrm{H} 5$ (32 g) registered maximum seed yield plant ${ }^{1}$ (Fig 1E and F).

\section{Biochemical parameters}

\section{Quantification of total carbohydrate}

All the accessions studied showed significant $(p<0.05)$ variation in the total carbohydrate content. Amongst the tested germplasm Shonamung-1 (64\%), amongst the mutants $\mathrm{M} 8(65 \%)$ and amongst the hybirds lines $\mathrm{H} 10, \mathrm{H} 11$, $\mathrm{H} 1, \mathrm{H} 2$ (65\% each respectively) had higher carbohydrate content than the rest (Fig $2 \mathrm{~A}, 3 \mathrm{~A}, 4 \mathrm{~A}$ ).

\section{Quantification of total starch}

The total starch content among accessions showed little significant $(p<0.05)$ variation. Shonamung1 showed maximum content of (58\%) starch (Fig 2B). M8, M17, M9, $\mathrm{M} 7$ and $\mathrm{M} 2$ along with $\mathrm{H} 11, \mathrm{H} 1$ and $\mathrm{H} 2$ recorded the highest starch content (59\% each respectivelty) (Fig 3B and 4B).

\section{Quantification of amylose content}




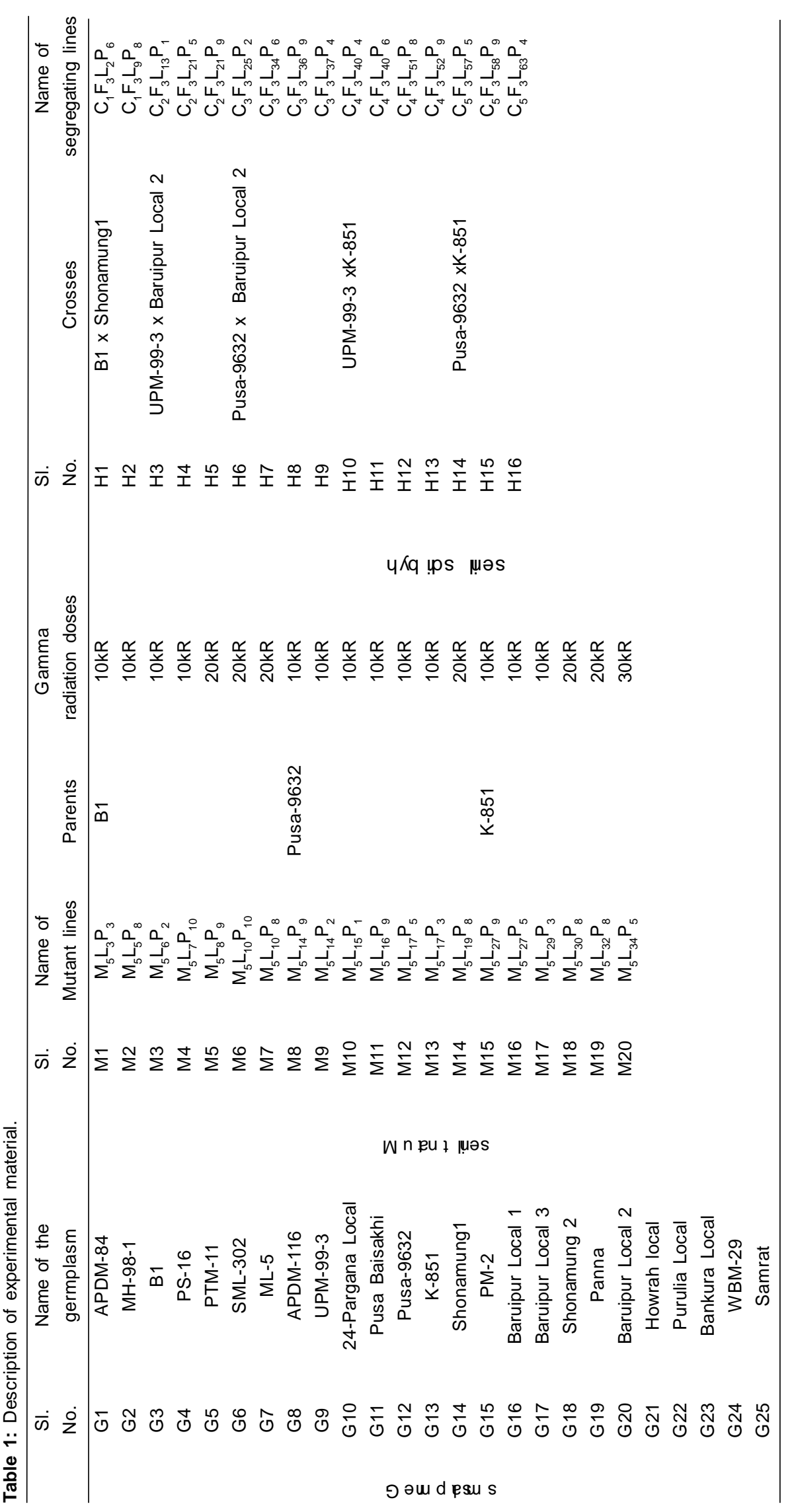


$(p<0.05)$ with an average value of $39.07 \%$. Shonamung 1 (45\%) showed a higher amylose content (Fig 2C). The average amylose content of both the hybirds lines (44\%) and the mutants (44\%) was more than the germplasms. Among the hybirds lines the highest amylose content (45\%) was recorded in $\mathrm{H} 2, \mathrm{H} 1, \mathrm{H} 10$ and $\mathrm{H} 11$ (Fig $4 \mathrm{C}$ ) and in mutants the highest amylose content (45\%) recorded in $\mathrm{M} 10$, M17, M13, M10, M8 and M2 (Fig 3C).

\section{Quantification of crude protein}

Crude protein content showed a significant $(p<0.05)$ variation among the accessions with an average of $26 \%$ (Fig 2D). PM2 (29.85\%) showed the highest crude protein content among the germplasms. The average crude protein in mutants and hybirds lines was 27\% (Fig 3D and 4D). The highest crude protein was recorded in M17, M13 and M18 among the mutants, whereas similar values were seen in $\mathrm{H} 10, \mathrm{H} 1$ and $\mathrm{H} 2$ among the hybirds lines.

\section{Quantification of total free amino acid}

The present study showed that the average value of total free amino acid content in studied germplasms was $0.89 \%$ of fresh weight of cotyledons which was lower than that in hybirds $(1.02 \%)$ and mutant $(1.03 \%)$ lines. With $0.98 \%$ content of total free amino acid, both Shonamung-1 and B1 showed higher free amino acid than the others (Fig 2E). For hybirds lines the highest total free amino acid was seen in $\mathrm{H} 9$ and $\mathrm{H} 16$ (1.11\%) (Fig 4E) and that for mutants in M16 $(1.20 \%)$ for every $100 \mathrm{~g}$ cotyledon fresh weight (Fig 3E).

\section{Quantification of total nitrogen}

A genotypic variation of the total nitrogen content among the germplasms showed that Shonamung $1\left(3.84{\left.\mathrm{~g} 100 \mathrm{~g}^{-1}\right)}\right.$ had the highest nitrogen content. The average nitrogen content of the germplasms $(3.1 \%)$ was lower than that of hybirds lines (3.75\%) and mutants (3.66\%) (Fig 2F). M8 (3.9\%) among the mutants and $\mathrm{H} 9, \mathrm{H} 15, \mathrm{H} 1$ (4\% each respectively) among the hybirds lines showed the highest nitrogen content (Fig 3F and 4F).

\section{Multivariate analysis \\ Principal component study}

In the present investigation, first two principle components with eigen values $<1$ contributed 81.32 per cent of the cumulative variability amongst all the mungbean accessions evaluated for 6 qualitative and 2 quantitative traits (Fig 5). The first principal component contributed maximum towards variability $(71.17 \%)$. Characters recorded the maximum variance in first principal component $(P C 1)$ reflects high carbohydrate and seed yield/plant of each accession. The second principal component (PC2) which described $10.14 \%$ of the total variance reflected significant loadings of crude protein (1.034) and total nitrogen (0.059), which were positively correlated that reflects $\mathrm{PC} 2$ describes crude protein and total nitrogen content of each accession. The PCA scores for eight parameters in the first two principal components were computed and plotted in graph to get the 2D scatter diagram (Fig 5). Moreover, depending on the PCA scores for sixty one accessions in the first two PCs with eigen value $>1$ were also plotted in the above mentioned 2D graph (Fig 5), which confirms the distribution of different accessions on the basis of each parameters studied. Accessions belong to the first and second quadrate was reported to be high yielder and carbohydrate rich. On the other hand, accessions of third quadrate were early maturing protein rich and of fourth quadrate was nitrogen and free amino acid rich.

\section{Cluster analysis}

Dendrogram based on all the studied parameters grouped the sixty one experimental materials into four clusters based on similarity of coefficients within 0 to 10 rescaled distances (Fig 6). Mean values of each cluster revealed that the accessions belong to the cluster III and IV is improved quality lines with early maturity duration and high yield.

\section{Estimates of correlation matrix}

The genotypic correlation matrix of the six biochemical

Table 2: Details of experimental locations.

\begin{tabular}{|c|c|c|c|}
\hline \multirow{2}{*}{ State: West Bengal, India } & \multicolumn{3}{|c|}{ Locations } \\
\hline & Baruipur & Arambagh & Udaynarayanpur \\
\hline Date of sowing & 12.3.2018 & 15.3.2018 & 20.3.2018 \\
\hline District & 24 Parganas (south) & Hooghly & Howrah \\
\hline Latitude & $22^{\circ} \mathrm{N}$ & $22.88^{\circ} \mathrm{N}$ & $22.72^{\circ} \mathrm{N}$ \\
\hline Longitude & $88.26^{\circ} \mathrm{E}$ & $88.78^{\circ} \mathrm{E}$ & $87.98^{\circ} \mathrm{E}$ \\
\hline Altitude (above sea level) & $9.75 \mathrm{~m}$ & $12 \mathrm{~m}$ & $7 \mathrm{~m}$ \\
\hline \multicolumn{4}{|l|}{ Avg temp. $\left({ }^{\circ} \mathrm{C}\right)$} \\
\hline March & 26.1 & 26.5 & 25.8 \\
\hline April & 28.4 & 28.6 & 27.4 \\
\hline May & 30.2 & 30.3 & 31.6 \\
\hline \multicolumn{4}{|l|}{ Avg rainfall (mm) } \\
\hline March & 26.5 & 18.6 & 20.5 \\
\hline April & 46.2 & 38.5 & 31.6 \\
\hline May & 100.5 & 81.3 & 49.2 \\
\hline Soil pH & 6.9 & 7.1 & 6.6 \\
\hline
\end{tabular}


constituents with seed yield plant ${ }^{-1}$ and days to maturity were studied in all the experimental materials (Table 3 ). Correlation study showed that total carbohydrate had significant positive correlation with amylose $(0.870)$, total free amino acid $(0.491)$ and total starch $(0.482)$ contents. Total starch showed positive significant correlation with amylose (0.582), total free amino acid (0.555) and seed yield (0.776), whereas, amylose content had significant positive correlation with total free amino acid (0.632), total nitrogen
(0.398) and seed yield (0.427). But both of them showed significant negative correlation with days to maturity $(-0.656$ and -0.438 respectively). Interestingly, days to maturity also showed significant negative correlation with seed yield plant ${ }^{1}$ $(-0.718)$.

Improved nutritional value of mungbean along with enhanced agronomic parameters (such as shorter maturity duration and higher seed yield) can have important implications in the food security programmes in Asia and
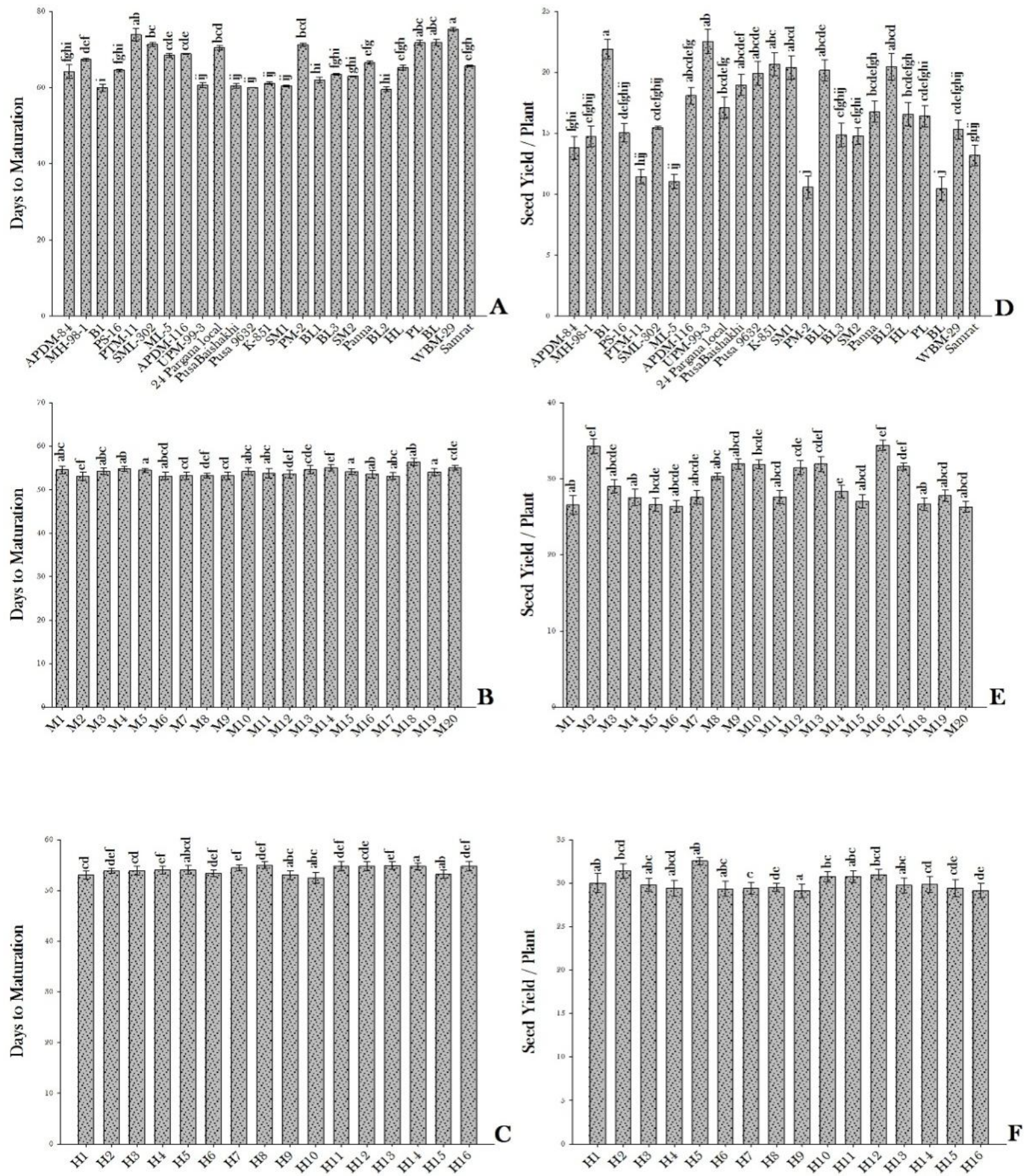

Fig 1: Evaluation the days to maturity and seed yield of germplasms ( $A$ and $D$ ), mutants ( $B$ and $E)$ and hybrids (C and $F)$. Small case alphabets represent significant differences between the samples at $p>0.05$. 

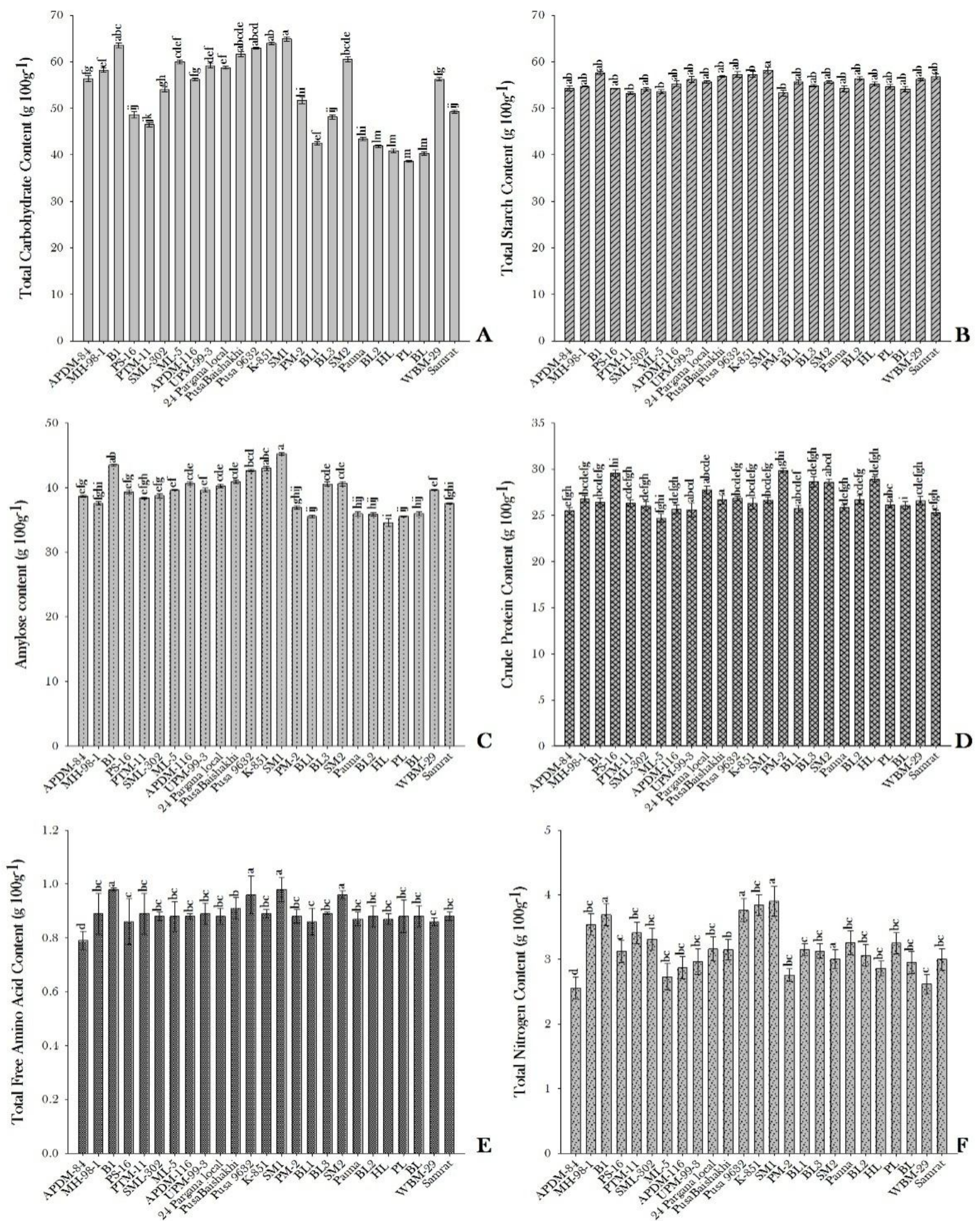

Fig 2: Estimation of the total carbohydrate $(A)$, starch $(B)$, amylose $(C)$, crude protein (D), free amino acid $(E)$ and total nitrogen $(F)$ content in 25 mungbeangermplasms studied. Small case alphabets represent significant differences between the samples at $p>0.05$. 
especially India. Induced mutation as well as hybridization programmes for crop improvement is an established practice worldwide. During the past seventy years, more than 2,252 mutant varieties have been officially released (Maluszynski et al., 2000). Significant improvements in mungbean have been made either through the use of mutation breeding or conventional hybridization programmes as seen in earlier works, but most of them were for quantitative characters (Lal and Mishra 2006). The objective of our present work was to screen a large population of mungbean accessions
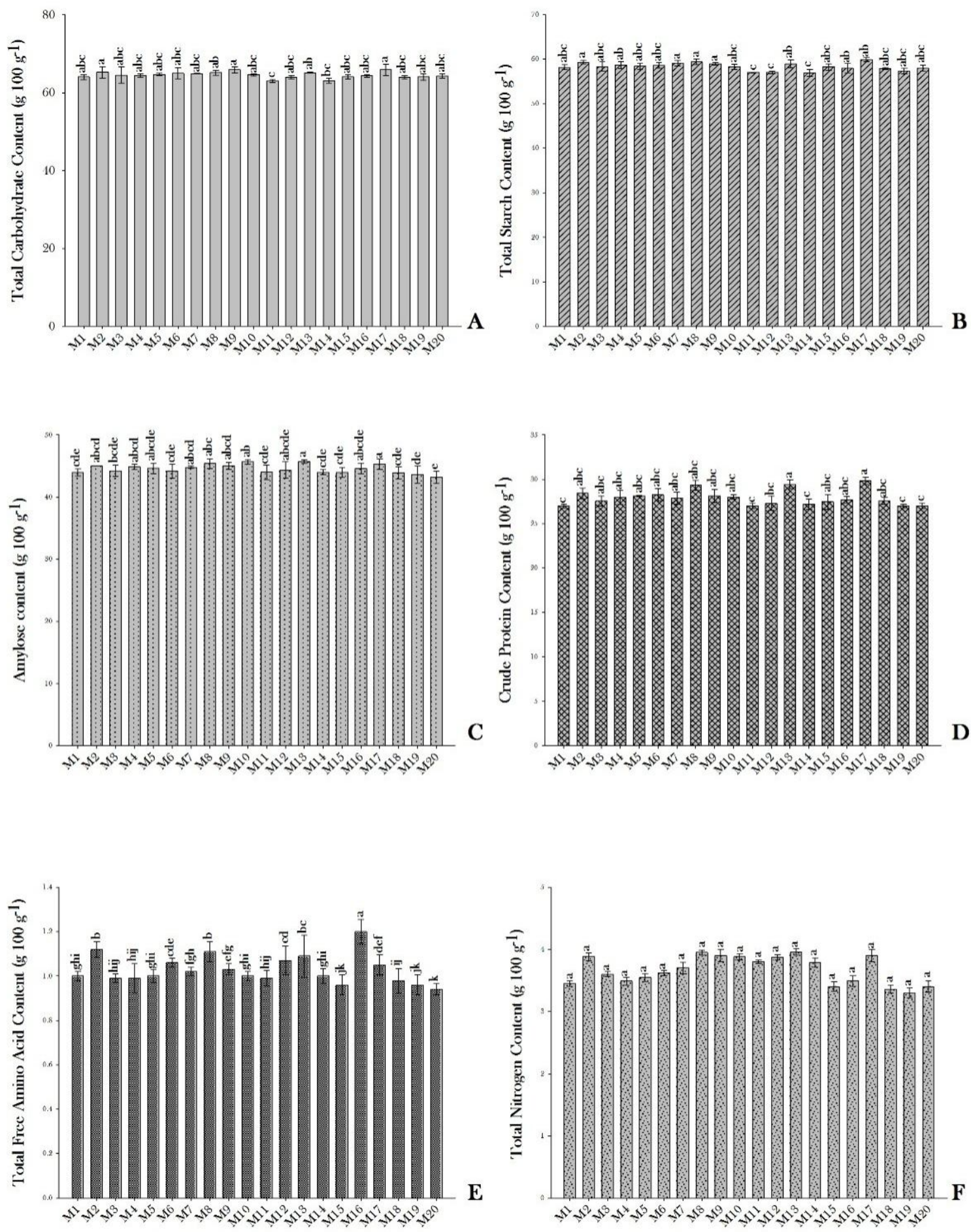

Fig 3: Estimation of the total carbohydrate $(A)$, starch $(B)$, amylose $(C)$, crude protein $(D)$, free amino acid $(E)$ and total nitrogen $(F)$ content in 20 mutant lines studied. Small case alphabets represent significant differences between the samples at $p>0.05$. 
based on nutritional qualities, collected from different geographical locations or derived from induced mutation or hybridization programmes.

In the present study, a total of sixty one accessions was studied, out of which twenty five were high productive short duration mungbean germplasms collected from different parts of India, twenty mutant lines $\left(\mathrm{M}_{5}\right)$ derived through gamma radiation induced mutation breeding and sixteen shybird lines $\left(\mathrm{F}_{3}\right)$ derived through the hybridization program were assessed for their maturity duration, seed yield and a
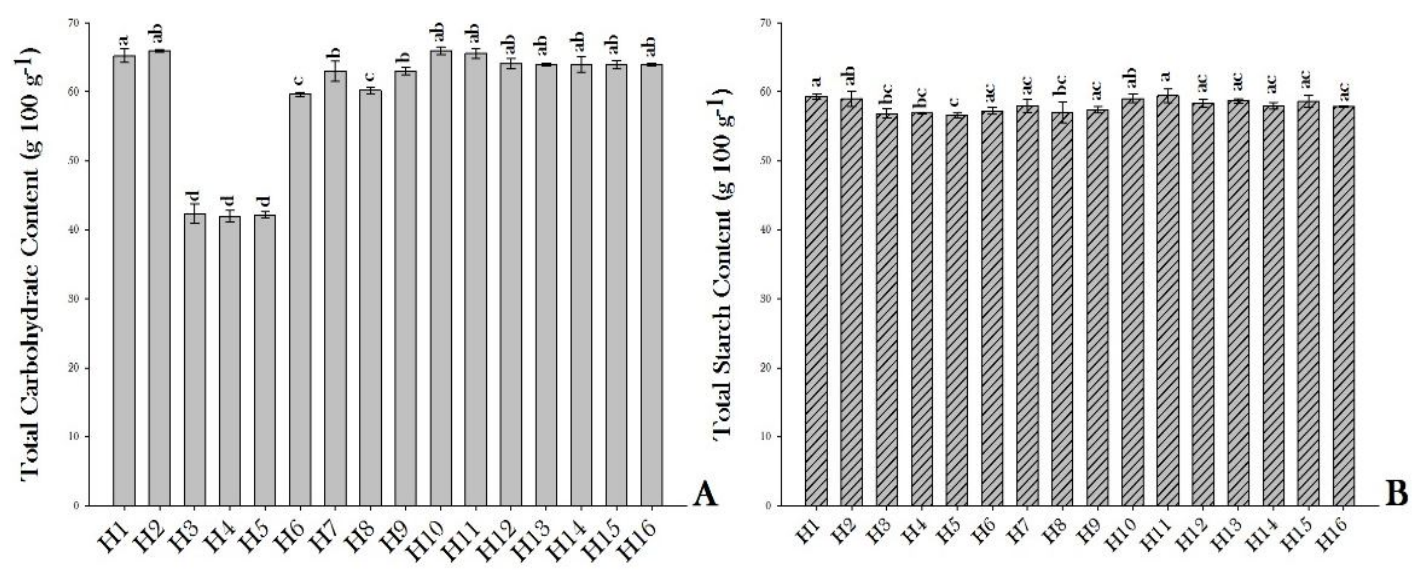

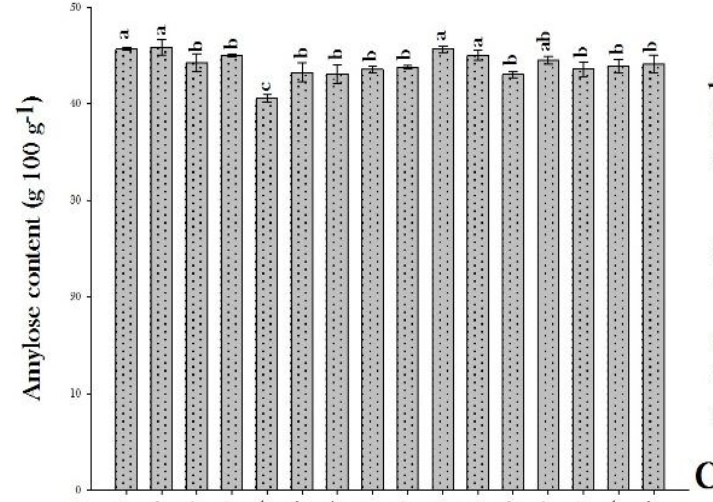

(2)
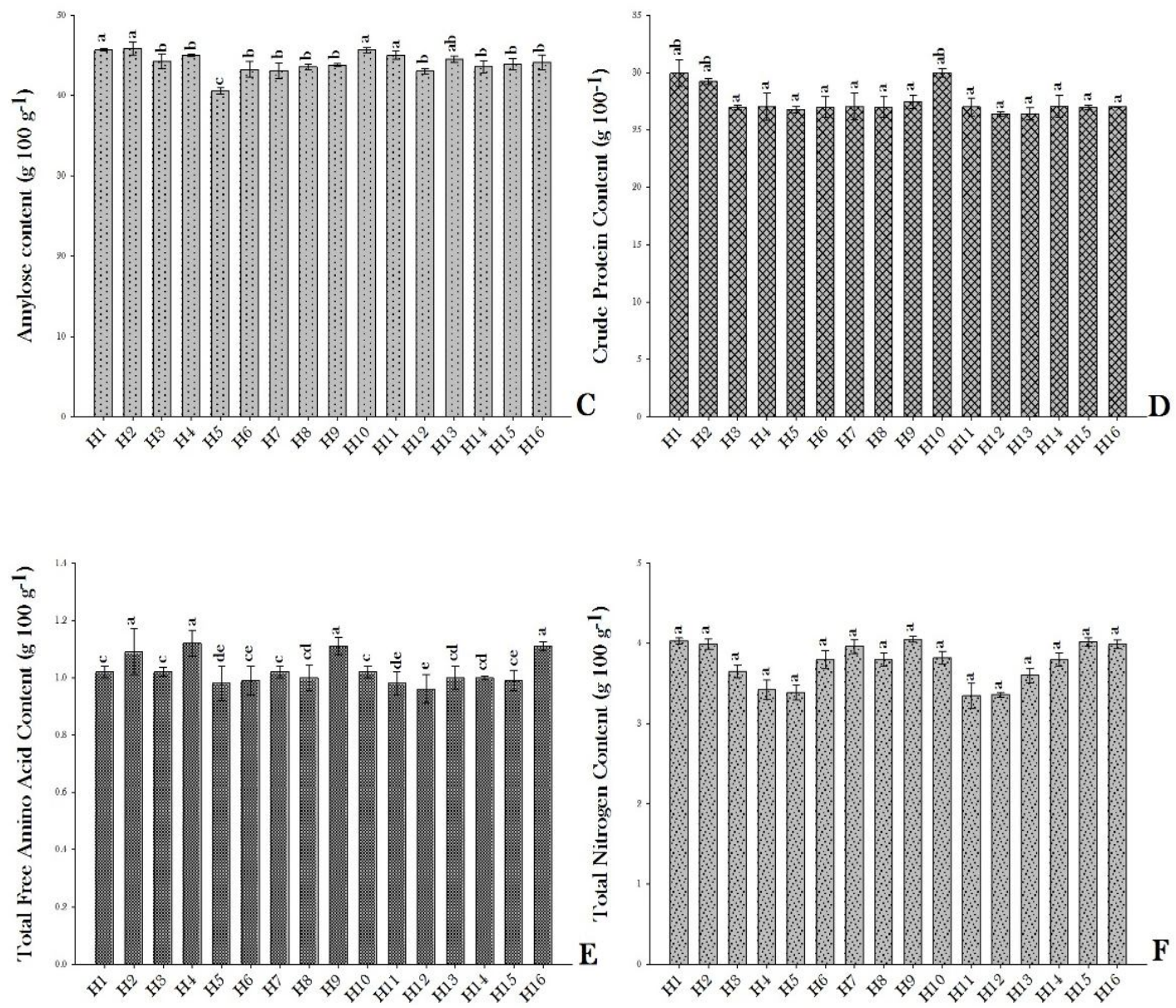

Fig 4: Estimation of the total carbohydrate $(A)$, starch $(B)$, amylose $(C)$, crude protein $(D)$, free amino acid $(E)$ and total nitrogen $(F)$ content in 16 hybrid lines. Small case alphabets represent significant differences between the samples at $p>0.05$. 
Towards Quest for Early Maturing Mungbean [Vigna radiata (L.) Wilczek] Lines with Improved Nutritional Quality and High Yield

Table 3: Correlation matrix for biochemical constituents of sixty one tested entries.

\begin{tabular}{|c|c|c|c|c|c|c|c|c|}
\hline & TC (\%) & TS (\%) & A (\%) & CP (\%) & TFA (\%) & TN (\%) & M (Days) & $S Y / P(g)$ \\
\hline TC (\%) & 1.000 & $0.482^{*}$ & $0.870^{* *}$ & -0.143 & $0.491^{*}$ & 0.218 & -0.381 & 0.337 \\
\hline TS (\%) & & 1.000 & $0.582^{* *}$ & -0.312 & $0.555^{\star *}$ & 0.345 & $-0.656^{* *}$ & $0.776^{* *}$ \\
\hline A (\%) & & & 1.000 & -0.203 & $0.632^{* *}$ & $0.398^{*}$ & $-0.438^{*}$ & $0.427^{*}$ \\
\hline CP (\%) & & & & 1.000 & -0.052 & 0.078 & $0.427^{\star}$ & -0.054 \\
\hline TFA (\%) & & & & & 1.000 & $0.647^{* *}$ & $-0.432^{*}$ & $0.427^{*}$ \\
\hline TN (\%) & & & & & & 1.000 & -0.302 & $0.409^{*}$ \\
\hline M (Days) & & & & & & & 1.000 & $-0.718^{* *}$ \\
\hline SY/P (g) & & & & & & & & 1.000 \\
\hline
\end{tabular}

TC: Total carbohydrate, TS: Total starch, A: Amylose, CP: Crude protein, TFA: Total free amino acid, TN: Total nitrogen, M: Days to maturity and SY/P: seed yield/plant $(\mathrm{g})$; ** denotes $1 \%$ level of significance and * denotes $5 \%$ level of significance.

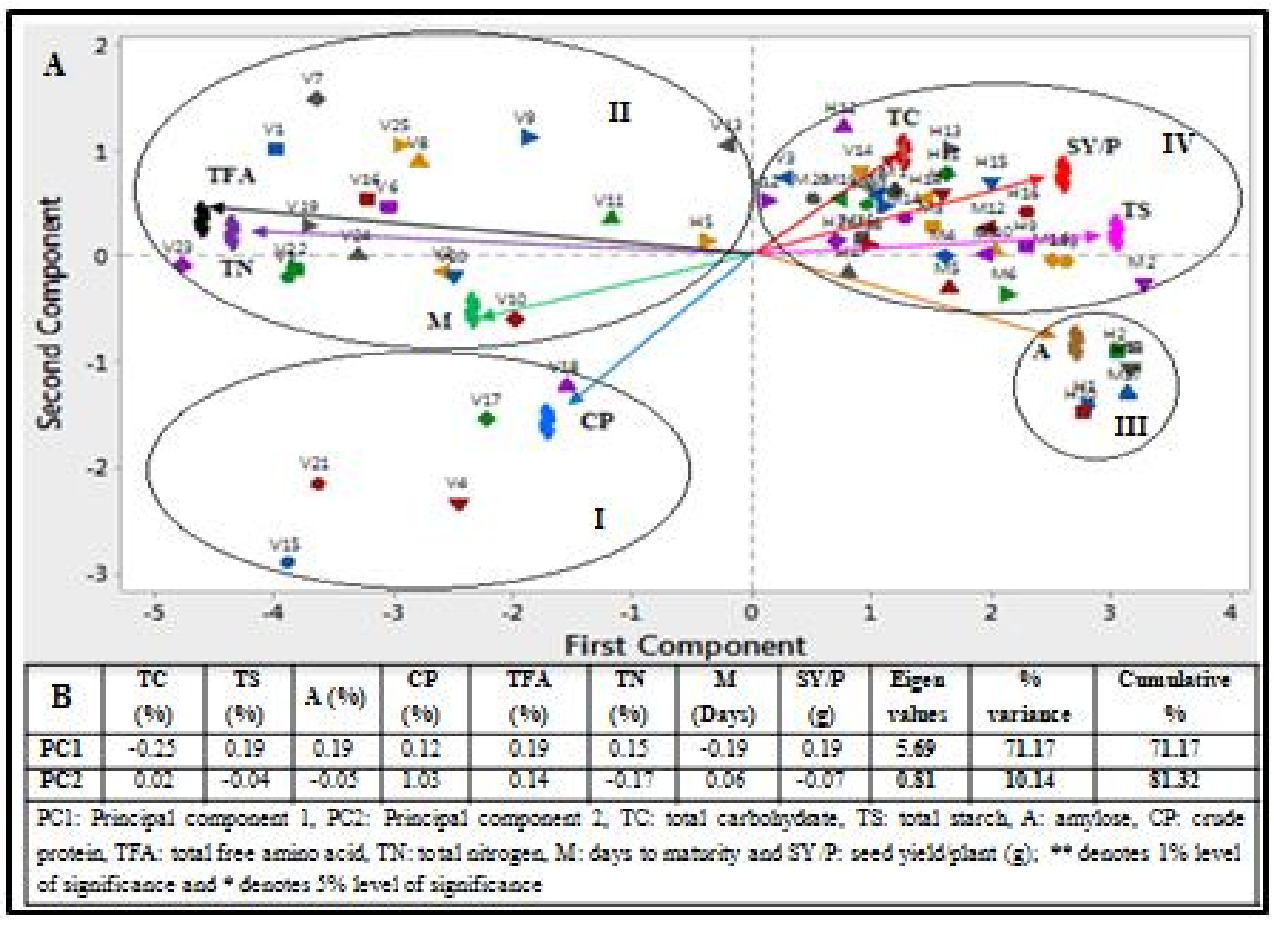

Fig 5: A. Two-dimensional plot showing relative position of germplasms of mungbean and tested parameters based on PCA scores.

B. principal components study.

number of quality parameters. Among the tested gamma induced mutant cultivars of mungbean in India and germplasms, B1, Pusa Baisakhi, Pusa 9632, K-851, Pakistan (Khan and Wani 2006; Sarkar and Kundagrami Shonamung-1 and Shonamung-2 outperformed others, in 2018). hybird lines also showed decreased maturity days having increased carbohydrate, starch, amylose, crude and among them $\mathrm{H} 5, \mathrm{H} 11$ and $\mathrm{H} 12$ showed increased protein, free amino acid and nitrogen content. Based on the two important agronomic parameters, i.e., days to maturity and seed yield plant $^{-1}$, three germplasms B1, Pusa 9632 and K-851, were taken up for mutation breeding and raising of mutant generations (Sarkar and Kundagrami 2018). Additionally, hybridization was done between some outperforming germplasms to produce hybird lines. In terms of maturation days, mutants showed maturity duration of less than 54 days, whereas seed yield plant ${ }^{-1}$ increased to over $30 \mathrm{gm}$ seeds plant ${ }^{-1}$. Therefore the mutation decreased the maturity duration and increased seed yield, in comparison to the respective controls. Early maturing and with increased yield was also seen in earlier studies, with number of seed yield plant ${ }^{-1}$.

Enhancement in quality parameters of mutants and segregating lines over the respective controls was seen in the present study. Typically mungbeans show a starch content in excess of $30 \%$ (Singh et al., 1989). All mutant and hybird lines showed increase of total carbohydrate, total starch and total amylose content. Our study showed a protein content of $25 \%-29 \%$ in the experimental materials, well in accordance with previous reported results (Butt and Batool 2010). The protein quality of a food depends on its digestibility and the concentration of essential amino acids. So, quantitative estimation of total free amino acid in mungbean seed is an important estimate. The average value 


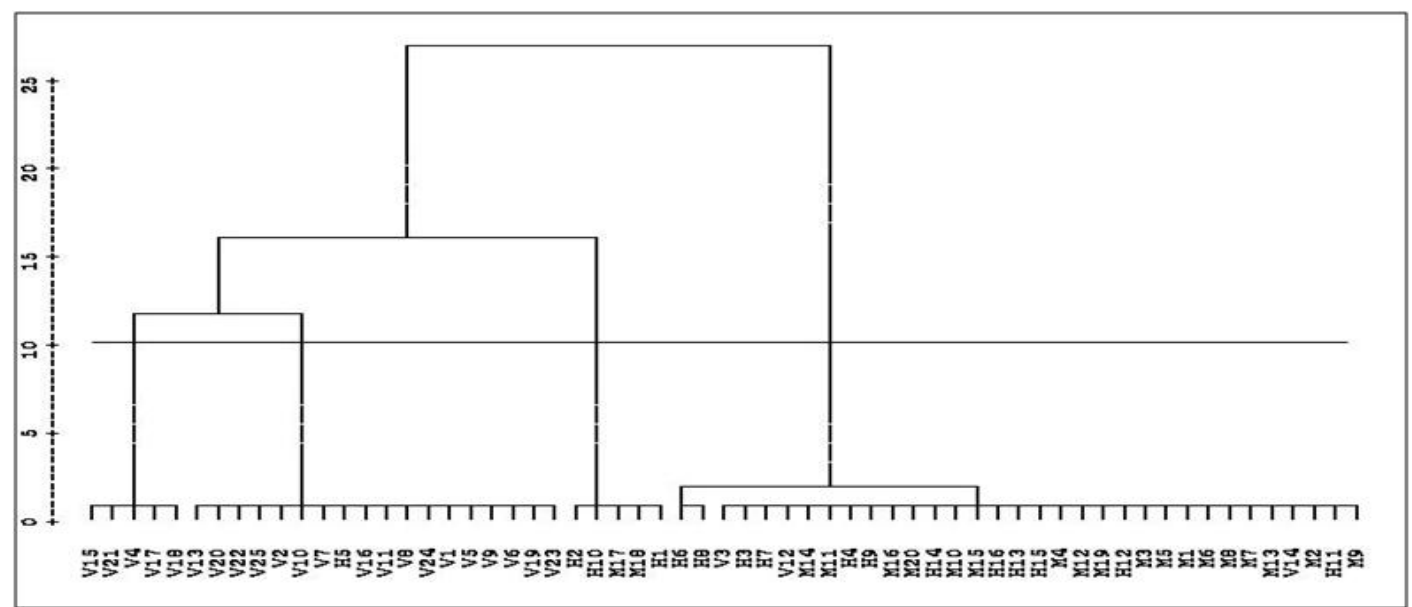

Fig 6: A dendrogram showing relationship between twenty five mungbean accessions and their selected $M_{5}$ and $F_{3}$ progenies based on unweighted pair group method with arithmetic mean (UPGMA) of Euclidean distances of their agronomic as well as biochemical parameters.

for total free amino acid of the germplasms, hybrids and mutants were $0.89 \%, 1.03 \%$ and $1.02 \%$ respectively, much higher than previously reported range of $0.88 \%-0.76 \%$ (Banusha and Vasantharuba 2013). Gopalan et al. (2007) reported that the nitrogen acquisition in mungbean seed is about $3.84 \mathrm{~g}$ per $100 \mathrm{~g}$ seed.

Multivariate statistics help to summarize the data and reduce the number of variables necessary to describe it (Anderson 1972). Principal component analysis (PCA) reflects the importance of the largest contributor to the total variation at each axis of differentiation (Sharma 1998). Principal Components (PCs) are independent of each other (Mohammadi and Prasanna 2003) and they describe the variability which was not elucidated by others. In this investigation, the total variability was explained by two PCs (Fig 5). This may indicate the contribution of many traits with higher level of correlation to explain the gross diversity. These findings are in line with the earlier findings of (Caldo et al., 1996; Chakravorty et al., 2013). The twenty five germplasms were found together in two groups while the mutants and hybird lines aggregated and remained together in two separate groups. This indicated that genotypicaly the mother germplasms and the derived mutants as well as hybrids were distinct based on the parameters studied. There was a significant improvement with regard to mutation or hybridization with respect to the original germplasms.

To group the accessions into various clusters, hierarchical cluster analysis was followed (Fig 6). Principal component scores were used as variables instead of parameters for clustering procedures, making the results equivalent to those from initially standardized data as the correlation matrix was used for principal component analysis. Based on the parameters studied, mean value of each cluster indicates that no single cluster, may be suitable for all the tested parameters. Dendogram revealed that high yielding early maturing nutrient rich lines could be found in cluster III and IV. PCA and cluster analysis together allowed a natural grouping of the genotypes (Kraic et al., 2009). Khodadadi et al. (2011) showed that cluster analysis based on PCA is a more precise indicator of differences among genotypes than cluster analysis not based on PCA.

Correlation study revealed that protein contents were recorded slightly negative correlations with seed yield, but positive with maturity duration (Table 3 ). This indicates that the germplasms with high protein contents are not essentially high seed yielding but early maturing. The result also suggested that there is possibility of selection for increased protein content without detrimental effect on seed yield (Govindaraj et al., 2009). Another report also registered negative correlation of protein with that of yield (Raturi et al. 2014). Interestingly, total nitrogen contents and total starch had highly significant positive correlation with seed yield suggesting that amount of starch and nitrogen of mungbean accessions can serve as an excellent selection marker for improving seed yield.

Induced mutation using physical and chemical mutagens is one way to create genetic variation resulting in new varieties with better characteristics. In our study we have found that both induced mutation and conventional hybridization had positive impact on the nutritional quality as well as seed yield and maturity duration of the mungbean crop. A previous report revealed that induced mutations in mungbean significantly affected yield and nutritional quality (Sandhu and Saxena 2003). Between the mutants and the hybird lines, the mutant lines were superior to segregating lines. Mutant M2, M7 (Control: B1), M8, M9, M13 (Control: Pusa 9632) and M17 (Control: K-851) were found to have improved quality parameters as well as short maturity duration ( $<55$ days) and increased seed yield (>30gm per plant).

\section{CONCLUSION}

This study successfully identified germplasms, mutants and hybird lines with improved quality parameters. It was evident from the results that germplasms B1, Pusa 9632, K-851, 
Shonamung-1 and Shonamung-2 can be excellent candidates for developing improved mungbean varieties through conventional and other breeding strategies. $\mathrm{H} 1, \mathrm{H} 2$, $\mathrm{H} 10$ and $\mathrm{H} 11$ hybrids as well as the mutants M2, M9, M12 and M17 showed promising results and can eventually be released as improved varieties after further multi-location trials in accordance with standard norms. Hence, it is beyond doubt that both conventional hybridization as well as induced mutation is highly successful in establishing mungbean varieties with improved agronomic and quality parameters.

\section{REFERENCES}

Anderson, T.W. (1972). An introduction to multivariate statistical analysis. Wiley eastern private limited. New Delhi, India. $512 \mathrm{p}$.

Anisha, G. and Prema, P. (2008). Reduction of non-digestible oligosaccharides in horse gram and green gram flours using crude a-galactosidase from Streptomyces griseoloalbus. Food Chemistry. 106: 1175-1179.

AOAC. (2000). Official Methods of Analysis. Association of Official Analytical Chemists, Washington, D.C. USA.

Banusha, S. and Vasantharuba, S. (2013). Effect of malting on nutritional contents of finger millet and mungbean. American-Eurasian Journal of Agricultural and Environmental Sciences. 13(12): 1642-1646.

Butt, M.S. and Batool, R. (2010). Nutritional and functional properties of some promising legumes protein isolates. Pakistan Journal of Nutrition. 9: 373-379.

Caldo, R.A., Sebastian, L.S. and Hernandez, J.E. (1996). Morphologybased genetic diversity analysis of ancestral lines of rice in Philippine rice cultivars. Philippine Journal of Crop Science. 21: 86-92.

Chakravorty, A., Ghosh, P.D. and Sahu, P.K. (2013). Multivariate analysis of phenotypic diversity of landraces of rice of West Bengal. American Journal of Experimental Agriculture. 3: $110-123$.

Department of Agriculture, Forestry and Fisheries. (2010). Mung Bean - Production Guideline. Cape Town: Department of Agriculture, Forestry and Fisheries. 16.

Dubois, M., Gilles, K.A., Hamilton, J.K., Reber, P.A. and Smith, F. (1956). Calorimetric method for determination of sugars and related substances. Analytical chemistry. 28: 350-356.

Garg, M., Sharma, N., Sharma, S., Kapoor, P., Kumar, A., et al. (2018). Biofortified crops generated by breeding, agronomy and transgenic approaches are improving lives of millions of people around the world. Frontiers in Nutrition. 5: 12. doi: 10.3389/fnut.2018. 00012.

Global hunger index. (2018). Global Hunger Index: India's ranking slips to 103 among 119 countries.(https://www.financial express.com/economy/india-ranks-103-onglobal hunger index /135035 2).

Gopalan, C., Ramasastri, B.V. and Subramanian, S.C. (2007). Nutritive Value of Indian Foods. Hyderabad, India: National Institute of Nutrition.

Govindaraj, M., Selvi, B. and Rajarathinam, S. (2009). Correlation studies for grain yield components and nutritional quality traits in pearl millet [Pennisetum glaucum (L.) R. Br.] germplasm. World Journal of Agricultural Science. 5(6): 686-689.
Grewal, A., Jood, S. and Yadav, R.K. (2006). Variability in physicochemical properties and chemical composition of newly released green gram cultivars. Haryana Agricultural University Journal of Research. 36(1): 65-70.

Hodge, J.E. and Hofreiter, B.T. (1962). In methods in carbohydrate chemistry. Food Chemistry. 59:131-157.

Khan, S. and Wani, M.R. (2006). MMS and SA induced genetic variability for quantitative traits in mungbean. Indian Journal of Pulses Research. 19: 50-52.

Khodadadi, M., Fotokian, M.H. and Miransari, M. (2011). Genetic diversity of wheat (Triticum aestivum L.) genotypes based on cluster and principal component analyses for breeding strategies. Australian Journal of Crop Science. 5(1): 17-24.

Kraic, F., Mocák, J., Roháèik, T. and Sokolovièová, J. (2009). Chemometric characterization and classification of new wheat genotypes. Nova Biotech. 9: 101-106.

Kshatriya, G.K. and Acharya, S.K. (2016). Gender disparities in the prevalence of undernutrition and the higher risk among the Young Women of Indian Tribes. PLoS ONE. 11(7): e0158308. https://doi.org/10.1371/journal.pone. 0158308.

Lal, N. and Mishra, R. (2006). Induced genetic variability and divergence in $\mathrm{M} 2$ generation of mungbean. Indian Journal of Pulse Research. 19(1): 47-49.

Lowry, D.H., Rosebrough, N.J., Farr, A.L. and Randall, R.J. (1951). Protein measurement with the folin phenol reagent. The Journal of Biological Chemistry. 193: 265-275.

Maluszynski, M., Nichterlein, K., Van Zanten, L. and Ahloowalia, B.S. (2000) Officially released mutant varieties-the $\mathrm{FAO} /$ IAEA database. Mutation Breeding Review. 12: 1-84.

Mohammadi, S.A. and Prasanna, B.M. (2003). Analysis of genetic diversity in crop plants-salient statistical tools and considerations. Crop Science. 43: 1235-1248.

Moore, S. and Stein, W.H. (1948). Photometric ninhydrin method for use in the chromatography of amino acids. The Journal of Biological Chemistry. 176: 367-388.

Nair, R.M., Yang, R.Y., Easdown, W.J., Thavarajah, D., Thavarajah, P., Hughes, J.A. and Keatinge, J.D.H. (2013). Biofortification of mungbean (Vigna radiata) as a whole food to enhance human health. Journal of the Science of Food and Agriculture. 93: 1805-1813.

Raturi, A., Singh, S.K., Sharma, V. and Pathak, R. (2014). Genetic variability and interrelationship among qualitative and quantitative traits in mungbean. Legume Research. 37(1): 1-10.

Sadasivam, S. and Manickam, A. (1996). Biochemical Methods, New Age International Publishers, Second Edition. 12-13 p.

Sandhu, J.S. and Saxena, A.K. (2003). Variability and association of nutritional quality traits of mungbean mutants. Indian Journal Pulses Research. 16(1): 54-55.

Sarkar, M. (2017). Breeding for high productive extra short duration lines of mungbean [Vigna radiata (L.) Wilczek] and their management for improved storability, viability, vigour and field performance. PhD Thesis, University of Calcutta, India.

Sarkar, M. and Kundagrami, S. (2017). Germplasm $\times$ environment interaction and stability for seed yield components and maturity duration in mungbean. International Journal of Current Research. 9(02): 45993-45998. 
Sarkar, M. and Kundagrami, S. (2018). Selection of high yielding, extra short duration lines of mungbean derived through gamma radiation. Indian Journal of Genetics. 78(2): 233241.

Sharma, J.R. (1998). Statistical and biometrical techniques in plant breeding. New Age International, New Delhi. 432 p.

Shobha Rani, T., Anil Kumar, G., Sravanti, K., Sameer Kumar, C.V., Maheswaramma, S., Ramesh, S. and Parimal, M. (2019). Heterosis Effects on Genetic Biofortification of Grain Iron and Zinc in Pearl Millet (Pennisetumglacum L.). Indian Journal of Agricultural Research. 53: 655-661
Singh, N. (2017). Pulses: An overview. Journal Food Science and Technology. 54(4): 853-857.

Singh, U., Voraputhapom, W., Rao, P.Y. and Jambunathan, R. (1989). Physicochemical characteristics of 39 pigeonpea and mung bean starches and their noodle quality. Journal of Food Science. 54: 1293-1297.

World Health organization. (2017). Children: Reducing Mortality. (http:// www.who. Int / news- room/ detail/ 15-09-2017). 